www.mdpi.com/journal/pharmaceuticals

Article

\title{
Mitochondrial FAD-linked Glycerol-3-phosphate Dehydrogenase: A Target for Cancer Therapeutics
}

\section{Gurmit Singh}

Department of Pathology and Molecular Medicine, McMaster University, 1280 Main Street West, Hamilton, Ontario L8S 4K1, Canada; E-Mail: singhg@mcmaster.ca;

Tel.: +1-905-525-9140 (ext. 28144); Fax: +1-905-777-7856

Received: 10 January 2014; in revised form: 29 January 2014 / Accepted: 6 February 2014 /

Published: 11 February 2014

\begin{abstract}
Imbalances in cellular redox state are frequently observed in cancer cells, and contribute significantly to cancer progression and apoptotic resistance. Hydrogen peroxide $\left(\mathrm{H}_{2} \mathrm{O}_{2}\right)$ is one reactive oxygen species (ROS) that is produced in excess within cancer cells. In this study, we investigated the mitochondrial glycerol-3-phosphate-dependent (GPD2) ROS production in PC-3 cells and demonstrated the importance of excessive $\mathrm{H}_{2} \mathrm{O}_{2}$ production on their survival. By exploiting the abnormal $\mathrm{H}_{2} \mathrm{O}_{2}$ production of PC-3 cells, we initiated a high-throughput screening of the Canadian Compound Collection, composed of 29,586 small molecules, targeting the glycerophosphate-dependent $\mathrm{H}_{2} \mathrm{O}_{2}$ formation in PC-3 cells. Eighteen compounds were identified to have significant inhibitory activity. These compounds have not been previously characterized as inhibitors of the enzyme. Six of these compounds were further analyzed in PC-3 cells and dose response studies displayed an inhibitory and anti-oxidative potency that ranged from $1 \mu \mathrm{M}$ to $30 \mu \mathrm{M}$. The results presented here demonstrate that inhibitors of mitochondrial GPD2 activity elicit anti-proliferative effects on cancer cells.
\end{abstract}

Keywords: drug discovery; glycerol-3-phosphate dehydrogenase; high-throughput screening; hydrogen peroxide; reactive oxygen species; prostate cancer

\section{Introduction}

Most cancer types display elevated levels of reactive oxygen species (ROS) [1]. Prostate cancer is characterized by innate oxidative stress, which is a hallmark of the aggressive phenotype of this disease [2]. Both healthy and malignant cells utilize hydrogen peroxide $\left(\mathrm{H}_{2} \mathrm{O}_{2}\right)$, a stable and diffusible 
form of ROS, as an effective signaling molecule in cellular mitogenic pathways [3-5]. However, prostate cancer cells exhibit abnormally increased production of $\mathrm{H}_{2} \mathrm{O}_{2}$, which influences many aspects of the disease, including proliferation, survival, and metastasis [2,6]. Mitochondria are recognized as a predominant source of ROS in both healthy and malignant cells, and within them, at least nine ROS-generating enzymes are known [7]. One mitochondrial enzyme, flavin-linked glycerol-3-phosphate ubiquinone oxidoreductase, also known as mitochondrial glycerol-3-phosphate dehydrogenase (GPD2) [EC 1.1.5.3], is capable of $\mathrm{H}_{2} \mathrm{O}_{2}$ production [8-11]. GPD2-dependent $\mathrm{H}_{2} \mathrm{O}_{2}$ formation has been reported in insect and mammalian mitochondria [9-11]. In isolated Drosophila mitochondria, 70\% of the total cellular $\mathrm{H}_{2} \mathrm{O}_{2}$ production was estimated to stem from GPD2 [10]. GPD2 emerged as a substantial source of $\mathrm{H}_{2} \mathrm{O}_{2}$ in the pro-oxidative environment of the prostate cancer cell lines PC-3, LNCaP, DU145, and CL1 [8]. In particular, PC-3 cells, which are derived from aggressive metastatic adenocarcinoma [12], displayed the highest GPD2 activity among the examined prostate cancer cell lines, generating up to 4-fold higher amounts of $\mathrm{H}_{2} \mathrm{O}_{2}$ compared to normal prostate epithelial cells [8].

GPD2 and the cytoplasmically-localized NAD-linked glycerol-3-phosphate dehydrogenase (GPD1) [EC 1.1.1.8] are the two components of the glycerophosphate shuttle, which, alongside the malate-aspartate transporter, build a secondary, rapidly operating biochemical mechanism utilized for the reoxidation of glycolytic-formed NADH. GPD2, localized on the outer surface of the inner mitochondrial membrane [13], unidirectionally channels the glycerol-3-phosphate-derived electrons in the mitochondrial inner membrane. In the pro-oxidative mitochondrial environment, GPD2 contributes to superoxide anion formation $\left(\mathrm{O}_{2}{ }^{-}\right)$, which further dismutates primarily via superoxide-dismutases to form $\mathrm{H}_{2} \mathrm{O}_{2}$. The molecular mechanism of GPD2-dependent ROS production has not yet been determined, although a recent report suggests that coenzyme Q may be the site of ROS generation [14].

Metabolically, GPD2 participates in glycolysis, gluconeogenesis, glycerol and lipid metabolism (triacylglycerol metabolism) [15]. The GPD2-dependent glycerol-3-phosphate oxidation and the glycerol-phosphate shuttle mechanism are implicated in the process of thermogenesis [16,17]. GPD2 is reported to exhibit a pathophysiological relationship to type II diabetes [18,19], possibly due to the involvement in the maintenance of the pancreatic $\beta$-cell redox status [20,21]. Impaired GPD2 activity was reported in type II diabetic patients [20] and mutations of the GPD2 gene were documented in families of patients with non-insulin-dependent diabetes [22]. Also, antibodies against GPD2 were detected in a large number of diabetic patients [23]. Furthermore, functional GPD2 defects have also been suggested in mild non-syndrome mental retardation [24,25]. Finally, various animal models of oxidative stress support the notion that mitochondrial-generated ROS may have a causal role in atherosclerosis and other cardiovascular diseases [26].

The role of GPD2 in producing ROS is a poorly investigated metabolic side-reaction with profound implications for the proliferation of prostate cancer cells. Consequently, we initiated an approach for the development of GPD2 inhibitors as potential cancer therapeutic agents. To exploit the abnormal $\mathrm{H}_{2} \mathrm{O}_{2}$ production of PC-3 cells [2,8], we propose a high-throughput screen (HTS) of the Canadian Compound Collection (CCC), composed of 29,586 small molecules, to target GPD2-dependent $\mathrm{H}_{2} \mathrm{O}_{2}$ formation in PC-3 cells. Active compounds will be further analyzed to determine their ROS-inhibiting parameters and the impact of $\mathrm{H}_{2} \mathrm{O}_{2}$ alteration on cancer cell proliferation. 


\section{Experimental}

\subsection{Cell Lines and Growth Conditions}

The PC-3 prostate cancer cells [12] served as a target for ROS inhibition. They were grown in $10 \mathrm{~cm}$ tissue culture dishes containing RPMI 1640 media (Invitrogen, Burlington, ON, Canada) supplemented with $10 \%$ fetal bovine serum (FBS), $1 \% 100 \mathrm{mM}$ sodium pyruvate, $1 \%$ antibiotic/antimycotic, and $1 \%$ $1 \mathrm{M}$ HEPES. Cells were incubated at $37^{\circ} \mathrm{C}$ and $5 \% \mathrm{CO}_{2}$ in a humidified environment. PNT1A cells [27] resembled the normal epithelial cell control, and were similarly cultured in RPMI 1640 media, with $10 \%$ FBS and $1 \%$ antibiotic/antimycotic, and incubated as above.

\subsection{Screening Library}

The library screened at McMaster University's High Throughput Screening (HTS) laboratory consisted of 29,586 compounds arrayed in 352 (96-well) plates as single compounds at $250 \mathrm{mM}$ in 5\% DMSO. The quality of all compounds in the CCC was assured by the vendors and the HTS laboratory to be greater than $95 \%$ pure. The library was screened at a constant 1:25 dilution with a $10 \mathrm{mM}$ final concentration of compounds in each well (yielding 0.2\% DMSO as final vehicle concentration). The library was screened over a 12-week period. For secondary screening, compounds 5108184, 5228270, 5477644, and 5543723 were purchased from ChemBridge (San Diego, CA, USA), and compounds RH02211 and KM04416 we purchased from Fisher Scientific Company (Ottawa, ON, Canada).

\subsection{High-Throughput Screening for Small Molecules Altering $\mathrm{H}_{2} \mathrm{O}_{2}$ Production}

In preparation for screening, cells were washed with $10 \mathrm{~mL}$ PBS, and trypsinized using $2 \mathrm{~mL}(1 \times)$ trypsin-EDTA solution in phosphate-buffered saline (PBS) for $5 \mathrm{~min}$ at $37^{\circ} \mathrm{C}$. Trypsinized cells from 3 tissue culture dishes were re-suspended in supplemented media $(8 \mathrm{~mL} /$ plate $)$ and transferred to a single sterile conical tube. Using a disposable hemacytometer (CELL-VU ${ }^{\circledR}$, Fisher Scientific, Pittsburgh, PA, USA), pooled cells from the conical tube were counted under an inverted microscope. A solution containing 5,000 cells/100 $\mu \mathrm{L}$ were transferred to a robotic reservoir using a BIOMEK FX liquid handler (Beckman Coulter Inc., Fullerton, CA, USA) equipped with a 96-channel head. These were transferred to 92 wells of 96-well clear tissue-culture treated microplates. The remaining 4 wells of the microplate received media alone (no cells). Plates were then incubated for $24 \mathrm{~h}$, after which the automated liquid handler removed the media, washed the wells once with PBS, and dispensed all compounds and controls.

After compound addition, the assay plates were incubated at room temperature for 15 min before performing the $\mathrm{H}_{2} \mathrm{O}_{2}$ detection assay. Extracellular $\mathrm{H}_{2} \mathrm{O}_{2}$ was assessed using Amplex ${ }^{\circledR}$ Red reagent (10-acetyl-3,7-dihydroxyphenoxazine, Invitrogen) which, in combination with HRP, detects $\mathrm{H}_{2} \mathrm{O}_{2}$ released from PC-3 cells to produce the red fluorescent oxidation product resorufin, quantifiable fluorometrically [28]. Each compound plate was tested in duplicate. $100 \mu \mathrm{L}$ of the Amplex ${ }^{\circledR}$ Red reagent/horseradish peroxidase (HRP) working solution in PBS $\left(25 \mu \mathrm{M}\right.$ Amplex ${ }^{\circledR}$ Red in DMSO, $0.1 \mathrm{U} / \mathrm{mL}$ HRP in PBS) were added to each well using a second automated liquid handler. The reaction was allowed to proceed at room temperature, protected from light, for a minimum of $1 \mathrm{~h}$ and a 
maximum of $3.5 \mathrm{~h}$. The cells were measured fluorometrically using the EnVision 2102 multilabel reader (Perkin Elmer, Waltham, MA, USA) in the continuous assay mode. The fluorescence was measured at $590 \mathrm{~nm}$ every $40 \mathrm{~min}$ to follow the kinetics of the reaction, using excitation and emission filters of $535 \mathrm{~nm}$ ( $25 \mathrm{~nm}$ bandwidth) and $600 \mathrm{~nm}$ ( $8 \mathrm{~nm}$ bandwidth), respectively.

PC-3 cells with vehicle only ( $0.2 \%$ DMSO) were used as screening positive controls. Medium only (with $0.2 \%$ DMSO) was found to be the best negative control for this assay during HTS. Use of $10 \mathrm{mM}$ FCCP, an ionophore [29] that reduces PC-3 cell $\mathrm{H}_{2} \mathrm{O}_{2}$ formation by up to $30 \%$, served as an intraplate reference control for the assay.

\subsection{Assay Optimization and Validation for High-Throughput Screening}

The $Z^{\prime}$-factor [30] for the assay was calculated to assess the variability of the method and the bandwidth between positive and negative controls according to the following equation, where $\sigma=$ standard deviation of positive $(p)$ and negative $(n)$ controls, $\mu=$ mean of positive $(p)$ and negative (n) controls:

$$
Z^{\prime} \text { factor }=1-\left[\frac{3 \sigma p+3 \sigma n}{\mu p-\mu n}\right]
$$

The wells containing the positive and negative controls were used to determine the relative activities per plate and to calculate the activity values for each well containing the compounds. The $Z^{\prime}$-factor for each plate was calculated to assess the intra-plate variability. The fluorescence unit data obtained from each well was calculated in absolute percentage of residual activity. The residual activities of the plate and of the replica plate were plotted against each other and the hit zone estimated as the total average minus the standard deviation.

\subsection{Identification of GPD2-Specific Inhibitors}

To identify selective inhibitors of GPD2-related $\mathrm{H}_{2} \mathrm{O}_{2}$ production, GPD2 enzyme was purified from PC-3 cell cDNA. A GPD2 construct (aa 43-727) was generated with an N-terminal Strep tagII sequence. Proteins were expressed in the bacterial overexpressing strain GJ1158 [31] and purified by strep-Tactin affinity chromatography. Individual samples of compounds were re-arrayed in 96-well plates and tested for GPD2 oxidoreductase activity. Recombinant GPD2 enzyme was added reactions were initiated with $30 \mathrm{mM}$ glycerol-3-phosphate and assayed by the reduction of resazurin (Sigma-Aldrich, Oakville, ON, Canada), an artificial electron acceptor. The plates were measured using the Cytofluor Series 4000 Fluorescence Plate Reader (Excitation/Emission $=530 \mathrm{~nm} / 590 \mathrm{~nm}$; Perseptive Biosystems, Framingham, MA, USA).

\subsection{Determination of $E_{50}$ Values}

For compounds in the hit zone of the HTS assay ( \pm 3 standard deviations) and showing GPD2 oxidoreductase inhibitory activity, follow-up analyses were performed. The $50 \%$ effective concentration ( $\mathrm{EC}_{50}$ ) for decreasing $\mathrm{H}_{2} \mathrm{O}_{2}$ production activity was assessed with Amplex ${ }^{\circledR}$ Red. The compounds were added at concentrations varying from $1 \times 10^{-5}$ to $0.2 \mathrm{M}$, and assays were conducted in quadruplicate. 


\subsection{Proliferation Assay}

In proliferation assays extending over a period of $72 \mathrm{~h}$, cells were initially seeded in 96-well plates at 5,000 cells/well in RPMI 1640 supplemented media. Cells were left undisturbed for $4 \mathrm{~h}$ prior to compound treatment. Compounds were dissolved in sterile PBS and added to the wells at the required concentrations. Bovine catalase (Sigma) was dissolved in PBS and sterilized by passage through $0.2 \mu \mathrm{m}$ filter. Following $72 \mathrm{~h}$ of growth, in the presence or absence of catalase or compound, colonies were formalin fixed, stained with crystal violet, washed, dried, developed with a 50\% ethanol PBS mixture, and optical density was measured at $570 \mathrm{~nm}$.

\subsection{Cytotoxicity Assays}

The cytotoxic percentage was determined by measuring lactate dehydrogenase release $24 \mathrm{~h}$ after addition of the small molecule compound using the CytoTox 96 non-radioactive cytotoxicity assay kit (Promega, Madison, WI, USA) following instructions provided by the manufacturer. Cells were seeded at 5,000 cells/well in the presence or absence of the compound. Metabolic activity of cells was also assessed fluorometrically using Alamar Blue reduction according to the manufacturer's instructions (Invitrogen) and trypan blue staining using hemocytometer counting to assess cell viability in the presence of inhibitors.

\subsection{Statistical Analysis}

All results were calculated from a minimum of three independent experiments and with replicates per experiment as indicated. Results were considered significant at $p<0.05$ as calculated by one-way single-factor ANOVA with Tukey's post-tests. Data analyses were conducted using GraphPad Prism (La Jolla, CA, USA).

\section{Results and Discussion}

GPD2 is a nuclear-encoded protein located at the outer surface of the inner mitochondrial membrane [13] and participates in lipolysis, gluconeogenesis and glycolysis [32]. We previously demonstrated that GPD2 activity is elevated in several human prostate cancer cell lines when compared with normal prostate epithelial cells [8,33]. GPD2 is a potent generator of ROS in prostate cancer cells and hence serves a pivotal role in the cancer's pro-oxidative phenotype [8,33]. Limiting the $\mathrm{H}_{2} \mathrm{O}_{2}$ stress in PC-3 cells affected their growth, indicating that elevated $\mathrm{H}_{2} \mathrm{O}_{2}$ production is necessary for the survival of this malignant cell type. As glycerophosphate-dependent $\mathrm{H}_{2} \mathrm{O}_{2}$ production is a significant source of ROS in PC-3 cells, we analyzed its potential as a drug-sensitive target in the current investigation. To date, GPD2 has not been considered a target for HTS due to its challenging physico-chemical properties [34]. In particular, its sub-cellular localization [13] and the difficulty in generating sufficient quantities of purified $[35,36]$, functional protein have limited its accessibility to small molecule screening approaches. However, knowing the GPD2-dependent pathophysiological characteristics of PC-3 cells, we addressed this issue by employing a whole-cell based HTS utilizing the prostate cancer cell line PC-3. 


\subsection{High-Throughput Screening for the iSolation of Compounds Altering $\mathrm{H}_{2} \mathrm{O}_{2}$ Production}

A cell-based high-throughput screening protocol successfully identified cell-permeable effector molecules actively altering $\mathrm{H}_{2} \mathrm{O}_{2}$ formation in PC-3 cells. Active compounds were defined as those reducing $\mathrm{H}_{2} \mathrm{O}_{2}$ production activity to a level of at least three standard deviations below or above the high control in both replicates (average high control $=98.4 \%, \sigma=14.35$ ). A total of 133 compounds were identified as hits (Figure 1), 9 of which have been discontinued by the supplier. Additionally, 20 compounds increased $\mathrm{H}_{2} \mathrm{O}_{2}$ production activity significantly. The identified molecules are chemically diverse and do not fit into one particular class of compounds. The Z'-factor for the HTS assay for $\mathrm{H}_{2} \mathrm{O}_{2}$ production was determined to be $0.66 \pm 0.13$, indicating an excellent assay and ensuring an adequate signal-to-noise ratio.

Figure 1. High-throughput screening of the Canadian Compound Collection for inhibitors of ROS formation in the PC-3 prostate cancer cell line. (A) Plot of the two screening replicates reported as percent residual activity relative to the average of the high controls. Hits were identified as molecules reducing the $\mathrm{H}_{2} \mathrm{O}_{2}$ activity to less than $50 \%$ in both replicates, a statistical cut-off three standard deviations below the high control mean. (B) Plot of the Z-factor values of the two replicates versus the plate number that demonstrates the robustness of the high-throughput screening assay.

(A)

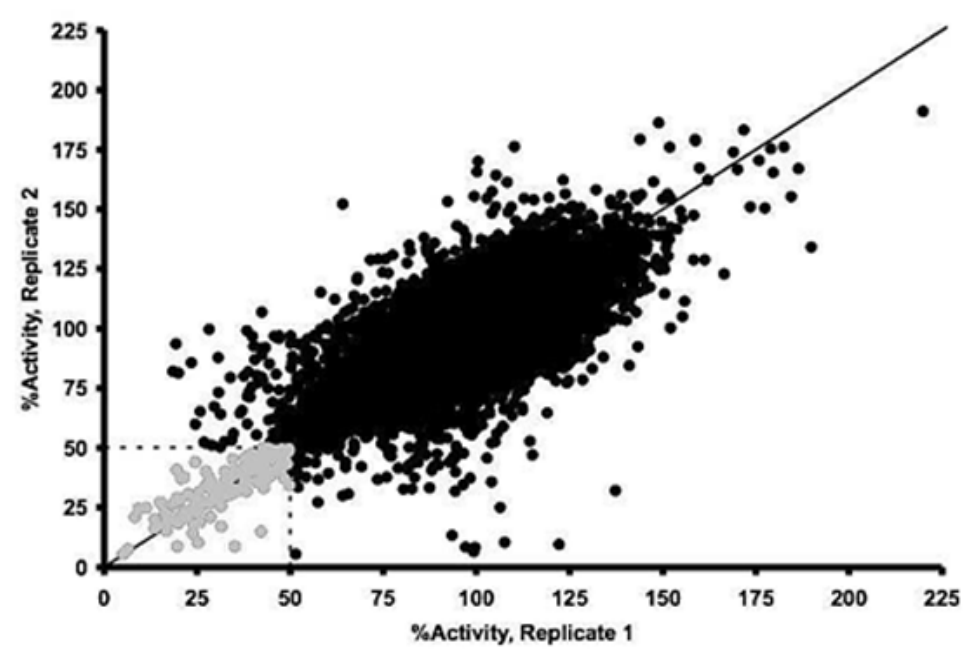

(B)

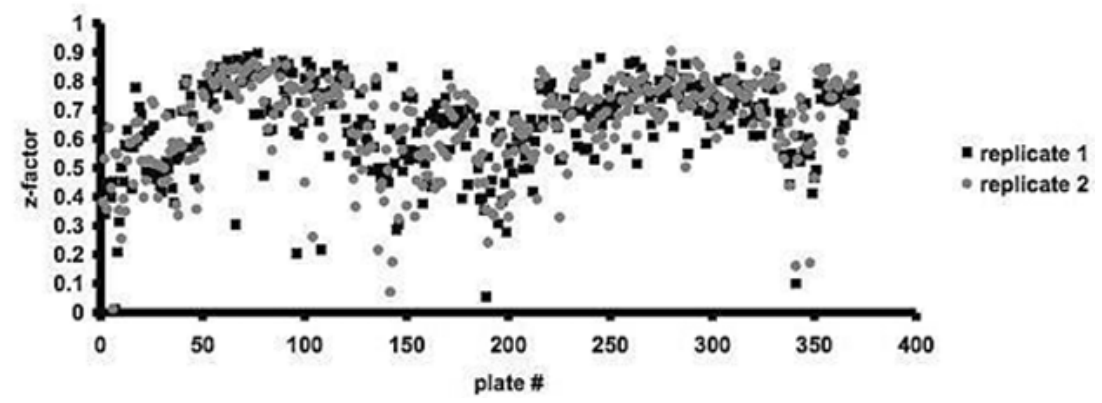

Among the identified molecules, several natural compounds with known antioxidative and anti-proliferative activities were found to inhibit $\mathrm{H}_{2} \mathrm{O}_{2}$ formation in PC-3 cells (carnosic acid, caffeic 
acid, rottlerin, gingerol, hypericin). A number of molecules act via G protein-coupled cell receptors (dopamine, H5T3, serotonin, glutamate, etc.), indicating interconnecting points between signaling cascades and the cellular ROS generation machinery. Molecules such as calmidazolium, a reported calmodulin antagonist, specify a role of intracellular $\mathrm{Ca}^{2+}$ levels in the ROS production. Mercurial molecules such as thimerosal and phenylmercuric acetate suggest the involvement of thiol residues in $\mathrm{H}_{2} \mathrm{O}_{2}$ formation.

\subsection{GPD2 Specificity}

Eighteen small molecule compounds from the inhibitors and one from the activators were identified as inhibiting the oxidoreductase activity of GPD2 to a level below $50 \%$ residual activity. From the known natural compounds of the CCC, lasalocid acid, caffeic acid, caffeic acid phenetyl ether (CAPE), rottlerin, carnosic acid, calmidazolium, propylnorapomorphine, SB 415286, and rhodomyrtoxin B emerged as effective GPD2 inhibitors, but were not selected for further screening in the current study as they had been examined by other groups. GPD2 activity was markedly inhibited by thiol-modifying mercurial reagents, such as thimerosal and phenylmercuric acetate, suggesting a physiological role for cysteine residues in GPD2's function. Six compounds from the ChemBridge and Maybridge compound sub-libraries that had not been examined in previous studies were identified and further assessed for oxidoreductase activity (Figure 2). The six selected compounds were further analyzed for $\mathrm{H}_{2} \mathrm{O}_{2}$ inhibitory effects (Figure 3 ) and all maintained an anti-oxidative potency that ranged from $1 \mu \mathrm{M}$ to $30 \mu \mathrm{M}$.

Figure 2. GPD2 activity inhibitors identified using HTS. The chemical structures of the six GPD2 activity inhibitors selected for follow-up analysis are shown, as well as their calculated $\mathrm{EC}_{50}$ values $\pm \mathrm{SEM}$.

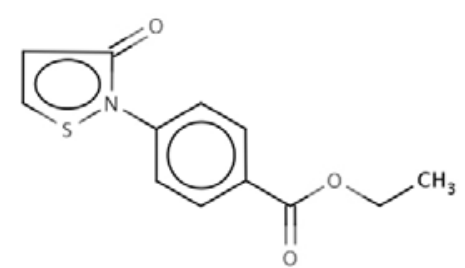

$\mathrm{KM} 04416(1.23 \pm 0.54 \mu \mathrm{M})$

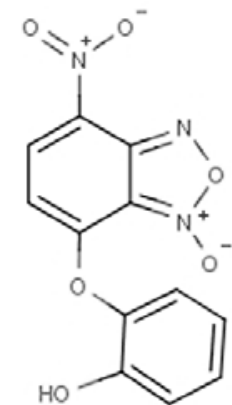

$5108184(13.34 \pm 2.47 \mu \mathrm{M})$

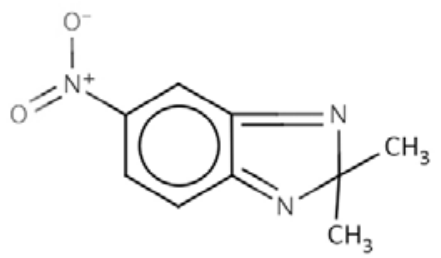

RH $02211(27.96 \pm 13.9 \mu \mathrm{M})$

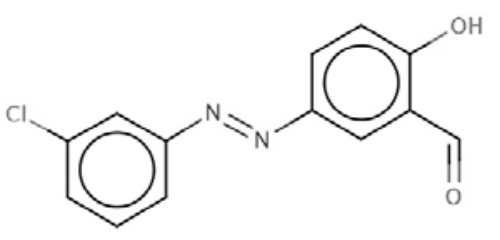

$5477644(8.6 \pm 2.89 \mu \mathrm{M})$

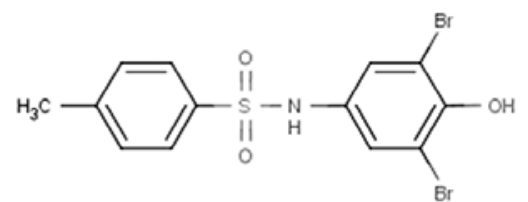

$5228270(7.48 \pm 3.71 \mu \mathrm{M})$

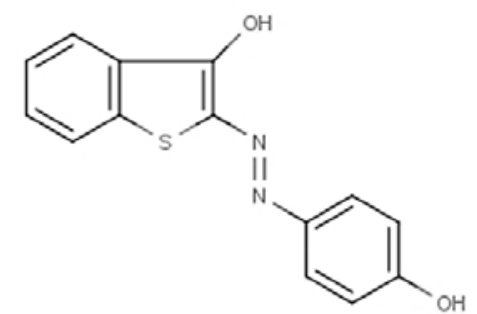

$5543723(4.45 \pm 1.2 \mu \mathrm{M})$ 
Figure 3. $\mathrm{H}_{2} \mathrm{O}_{2}$ activity inhibition curves for the most potent small molecule GPD2 inhibitors. Each curve represents the mean \pm SEM of three independent experiments with six wells per experiment. The curve fit was calculated using a non-linear fit $\log \left(\mathrm{C}_{\text {inhibitor }}\right)$ versus normalized response.
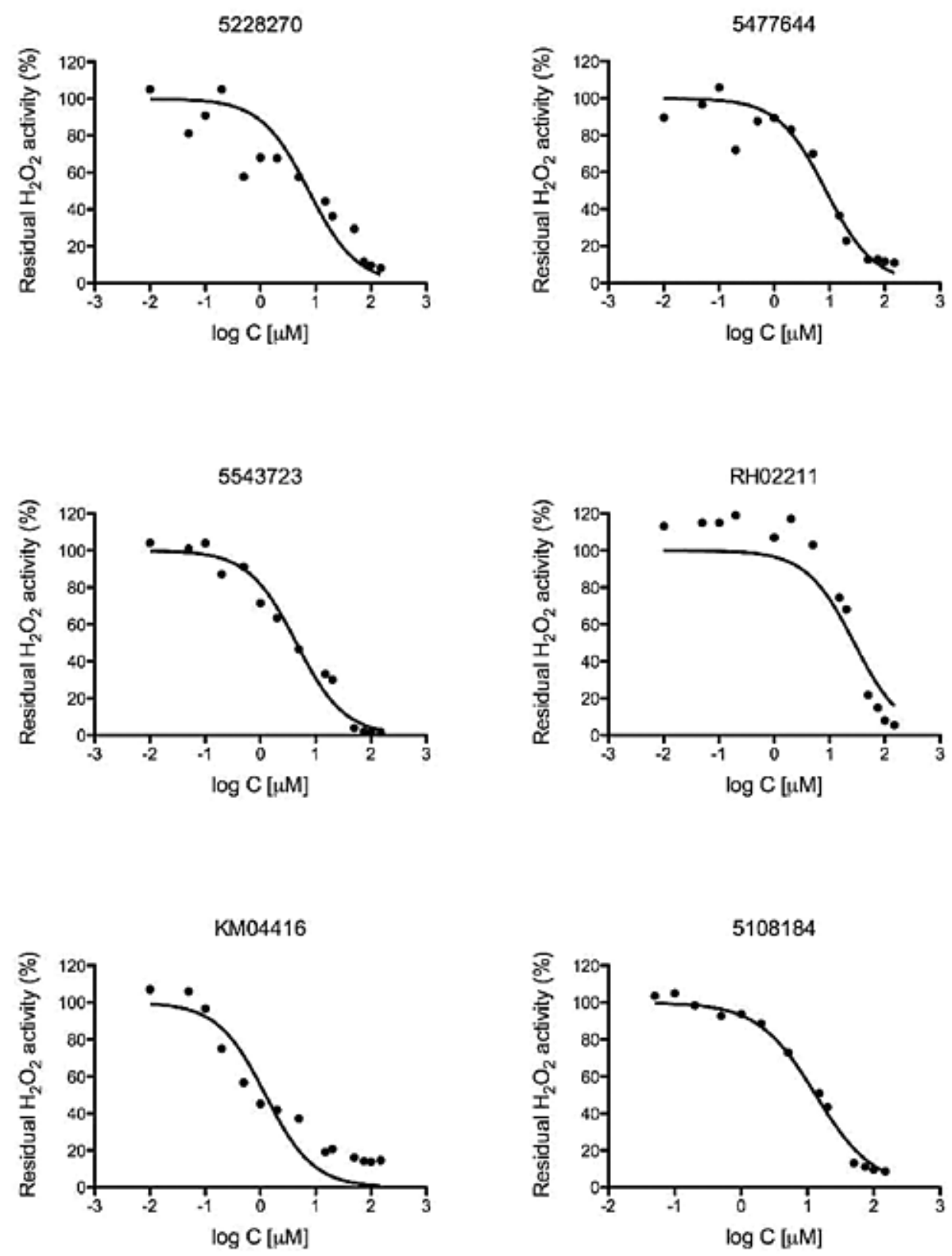

\section{3. $\mathrm{H}_{2} \mathrm{O}_{2}$ is Required for PC-3 Cell Growth}

PC-3 cells constitutively produce high amounts of $\mathrm{H}_{2} \mathrm{O}_{2}$ that diffuses into the extracellular space [8]. We evaluated the importance of this abnormal PC-3 characteristic for cell survival through the addition of sterile bovine catalase to the culture media [37]. The growth of PC-3 cells was inhibited in a dose-dependent manner; exclusion of this treatment by incubation or heat inactivation of the enzyme reversed this effect (Figure 4). Comparison with normal prostate epithelial cells PNT1A [27] the evaluation of the $50 \%$ inhibitory concentration of catalase confirmed that PC-3 cells produce significantly higher amounts of $\mathrm{H}_{2} \mathrm{O}_{2}\left(\mathrm{IC}_{50}=580 \mathrm{U} / \mathrm{mL}\right)$ compared to PNT1A $\left(\mathrm{IC}_{50}=75 \mathrm{U} / \mathrm{mL}\right)$. 
Figure 4. Growth effects of $\mathrm{H}_{2} \mathrm{O}_{2}$ elimination on PC-3 and PNT1A cells. Cell numbers were measured using crystal violet following a $72 \mathrm{~h}$ continuous exposure, and are displayed as \% cell growth compared to untreated cells. The displayed data represent the average \pm SEM of three independent experiments. Dose-dependent growth inhibition by catalase was observed in both cell lines, with PC-3 cells requiring higher concentration of catalase $\left(\mathrm{IC}_{50}=580 \pm 160 \mathrm{U} / \mathrm{mL}\right)$ to block cell proliferation, and PNT1A cells requiring lower concentration of catalase $\left(\mathrm{IC}_{50}=75 \pm 40 \mathrm{U} / \mathrm{mL}\right)$. The $\mathrm{IC}_{50}$ values were calculated using curve fit (GraphPad Prism) and applying a non-linear fit $\log \left(\mathrm{C}_{\text {inhibitor }}\right)$ versus normalized response.

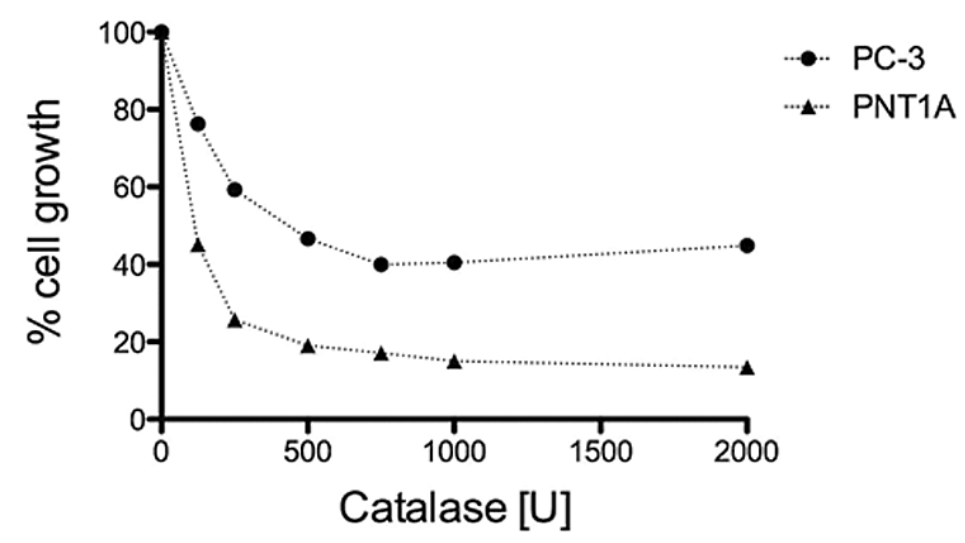

\subsection{GPD2 Activity Inhibitors Impact Survival of Prostate Cancer Cells}

The six selected compounds were analyzed for growth inhibition effects in PC-3 cells. Compounds 5108184, RH0211 and KM04416 displayed up to 30\% cytotoxicity (Figure 5) as assessed by lactate dehydrogenase release (CytoTox ${ }^{\circledR}$ assay). However, no cytotoxic effects were detected using the Alamar Blue cytotoxicity assay and Trypan Blue cell counts (data not shown).

Initially, the cell-based assay identified cell-permeable oxidative stress effectors. Using sub-libraries with molecules of known properties and modes of action we unveiled peculiarities of the molecular network involved in the ROS generating machinery. Dysregulation of mitochondrial $\mathrm{Ca}^{2+}$ homeostasis is recognized to play a key role in several pathologies, including ROS generation. G-protein signaling constitutes an interface between physiological responses and oxidative stress responses. Many small molecule metabolites with messenger functions (dopamine, H5T3, serotonin, glutamate, etc.) influence paracrine signaling for redox homeostasis, and affect the level of oxidative stress experienced by prostate cancers.

Among the various compounds identified in this study a number of known herbal antioxidants also emerged. Due to their high tolerability and low toxicity, they were earlier described in several studies as chemopreventative compounds and have received increasing attention due to their anti-initiating and/or anti-promoting effects on tumour growth. Based on chemical uniqueness, we subjected the six most novel substances from this study to further screening and evaluated their ability to affect PC-3 cell growth. Inhibition of GPD2-derived $\mathrm{H}_{2} \mathrm{O}_{2}$ production impaired PC-3 cell growth and survival in vitro. 
Figure 5. Effect of GPD2 activity inhibitors on the growth of PC-3 and PNT1A cells. Normal and malignant prostate epithelial cell lines were cultured in the presence of $10 \mu \mathrm{M}$ inhibitors for $72 \mathrm{~h}$. The data are displayed as \% cell growth compared to untreated cells. Results represent the average \pm SEM of five independent experiments with eight wells per experiment. $10 \mu \mathrm{M}$ cisplatin was used as a cytotoxic agent positive control. All GPD2 inhibitors and cisplatin inhibited PC-3 cell proliferation significantly $(p<0.05$, Tukey's multiple comparison test). Molecules 5477644, 5547644, KM04416 and cisplatin inhibited PNT1A cell proliferation significantly $(p<0.05)$.
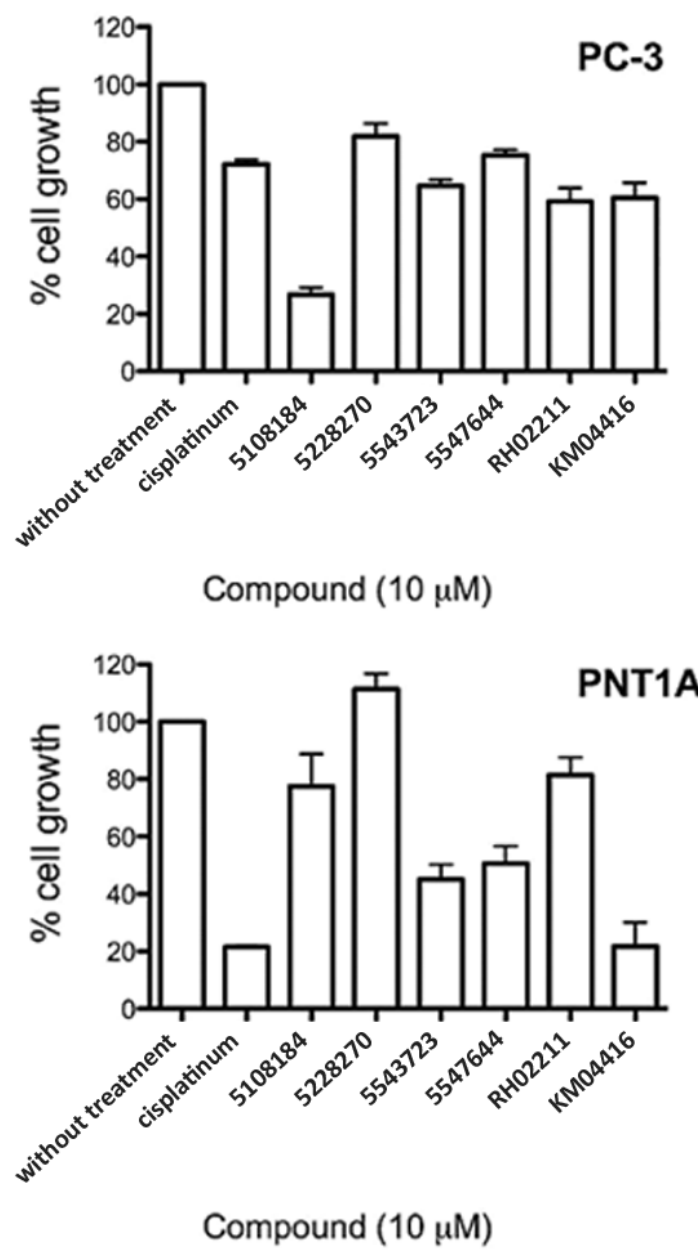

In our analysis, all the tested small molecules emerged as promising compounds with several features underlining their suitability. They significantly inhibited glycerol-3-phosphate oxidoreductase activity, $\mathrm{H}_{2} \mathrm{O}_{2}$ production, and $\mathrm{PC}-3$ cell growth at relatively low concentrations $(10 \mu \mathrm{M})$. Molecule 5108184 (a benzoxadiazole derivative) inhibited PC-3 cell growth by up to $70 \%$ after 3 days of treatment, whereas RH02211 (a benzimidazole derivative), 5477644 (a hydroxybenzaldehyde derivative), and KM04416 (an isothiazolone derivative) inhibited growth by 50\%. Compound 5228270 (a methylbenzenesulfonamide derivative) and 5543723 (a benzothiophene derivative) demonstrated up to $30 \%$ growth inhibition. They all impacted the pro-oxidative phenotype of PC-3 cells at low concentrations $\left(\mathrm{EC}_{50}\right.$ ranging between 1 and $\left.30 \mu \mathrm{M}\right)$. Additionally, 5108184, 5228270, and RH02211 showed no adverse effects on PTN1A cells. 
Although the molecules identified in this study display inhibition of glycerophosphate-dependent $\mathrm{H}_{2} \mathrm{O}_{2}$ formation, other modes of action cannot to be excluded at the current stage of our research. Due to their chemical structures, these inhibitors may impair cell function by forming covalent bonds with reactive groups in other biologically important molecules. Fortuitously, derivative analogs of the identified compounds illustrate anti-tumour activity by glutathione S-transferase [38] (benzoxadiazoles) and topoisomerase inhibition [39] (benzimidazoles). The low $\mathrm{IC}_{50} / \mathrm{EC}_{50}$ values make these molecules strong candidates for further investigations of the mechanism of action. Discovering new drug targets for cancer therapy is a significant aim of cancer research.

Early biochemical studies revealed elevated levels of GPD2 activity in fast-growing, undifferentiated tumours, such as hepatomas. In slow-growing, differentiated tumours, GPD2 activity was at normal or slightly reduced levels [40-43]. GPD1, on the other hand, was reported at a normal level in well-differentiated tumours, and was diminished or absent in fast-proliferating, undifferentiated tumours [40,44-48]. Additionally, the fact that GPD2 is involved in glycolysis/gluconeogenesis and lipolysis/lipid biosynthesis with significant pleiotropic effects on lipid accumulation and intracellular glucose homeostasis [32] underlines the metabolic importance of this enzyme in malignancies. Particular prostate cancers are characterized by a low rate of glycolysis and an increased rate of lipolysis [49]. $\mathrm{H}_{2} \mathrm{O}_{2}$ production from GPD2 may also have molecular implications in cardiovascular disease [50] and atherosclerosis development [51].

Mitochondrial enzymes have been the focus of attention, especially in recent years, as mitochondria play a characteristic role in cell metabolism and cancer development, and specific cancer inhibition may possibly be achieved at this cellular locus [52,53]. Evidence suggests that an excessive increase in ROS levels, often observed in cancer cells, influence various properties of these malignant cells [1]. Therefore, manipulating ROS generation in malignant cells may be a plausible means to control cancer progression [54]. However, the complex relationship between ROS and antioxidant enzyme activity suggests that further characterization of enzyme kinetics will be required. Molecules that limit the oxidative stress of malignancies at the source may deprive tumour cells of ROS-induced growth signaling pathways, and therefore could have the potential to cause growth arrest.

\section{Conclusions}

We have isolated a series of promising molecules that have the potential to lead to the development of novel anti-proliferative agents. In addition to their potential usage as anti-cancer drugs, the small molecules identified here could be developed into valuable tools for analyzing the catalytic mechanisms of GPD2 and probing its ROS-generating mechanism at the molecular level. A thorough functional understanding of GPD2 may lead to drug development in other disease models, like diabetes and atherosclerosis.

\section{Acknowledgments}

Small molecule screening was carried out at McMaster University's High Throughput Screening laboratory. Pierre Laflamme adapted the PC-3 cell culture conditions and Amplex ${ }^{\circledR}$ Red detection assay to the HTS format. Mohit Sharma assisted with human cell culture. Athanasios Paschos evaluated the HTS results and generated recombinant GPD2. 
This work was supported by the Canadian Institutes of Health Research (CIHR) to G.S.

\section{Conflicts of Interest}

The author declares no conflict of interest.

\section{References}

1. Liou, G.Y.; Storz, P. Reactive oxygen species in cancer. Free Radic. Res. 2010, 44, 479-496.

2. Kumar, B.; Koul, S.; Khandrika, L.; Meacham, R.B.; Koul, H.K. Oxidative stress is inherent in prostate cancer cells and is required for aggressive phenotype. Cancer Res. 2008, 68, 1777-1785.

3. Finkel, T. Reactive oxygen species and signal transduction. IUBMB Life 2001, 52, 3-6.

4. Irani, K.; Xia, Y.; Zweier, J.L.; Sollott, S.J.; Der, C.J.; Fearon, E.R.; Sundaresan, M.; Finkel, T.; Goldschmidt-Clermont, P.J. Mitogenic signaling mediated by oxidants in Ras-transformed fibroblasts. Science 1997, 275, 1649-1652.

5. Irani, K. Oxidant signaling in vascular cell growth, death, and survival: A review of the roles of reactive oxygen species in smooth muscle and endothelial cell mitogenic and apoptotic signaling. Circ. Res. 2000, 87, 179-183.

6. Polytarchou, C.; Hatziapostolou, M.; Papadimitriou, E. Hydrogen peroxide stimulates proliferation and migration of human prostate cancer cells through activation of activator protein-1 and up-regulation of the heparin affin regulatory peptide gene. J. Biol. Chem. 2005, 280, 40428-40435.

7. Andreyev, A.Y.; Kushnareva, Y.E.; Starkov, A.A. Mitochondrial metabolism of reactive oxygen species. Biochemistry 2005, 70, 200-214.

8. Chowdhury, S.K.; Gemin, A.; Singh, G. High activity of mitochondrial glycerophosphate dehydrogenase and glycerophosphate-dependent ROS production in prostate cancer cell lines. Biochem. Biophys. Res. Commun. 2005, 333, 1139-1145.

9. Kwong, L.K.; Sohal, R.S. Substrate and site specificity of hydrogen peroxide generation in mouse mitochondria. Arch. Biochem. Biophys. 1998, 350, 118-126.

10. Miwa, S.; St-Pierre, J.; Partridge, L.; Brand, M.D. Superoxide and hydrogen peroxide production by Drosophila mitochondria. Free Radic. Biol. Med. 2003, 35, 938-948.

11. Mracek, T.; Pecinova, A.; Vrbacky, M.; Drahota, Z.; Houstek, J. High efficiency of ROS production by glycerophosphate dehydrogenase in mammalian mitochondria. Arch. Biochem. Biophys. 2009, 481, 30-36.

12. Kaighn, M.E.; Narayan, K.S.; Ohnuki, Y.; Lechner, J.F.; Jones, L.W. Establishment and characterization of a human prostatic carcinoma cell line (PC-3). Invest. Urol. 1979, 17, 16-23.

13. Klingenberg, M. Localization of the glycerol-phosphate dehydrogenase in the outer phase of the mitochondrial inner membrane. Eur. J. Biochem. 1970, 13, 247-252.

14. Mracek, T.; Holzerova, E.; Drahota, Z.; Kovarova, N.; Vrbacky, M.; Jesina, P.; Houstek, J. ROS generation and multiple forms of mammalian mitochondrial glycerol-3-phosphate dehydrogenase. Biochim. Biophys. Acta 2014, 1837, 98-111. 
15. Saheki, T.; Inoue, K.; Ono, H.; Katsura, N.; Yokogawa, M.; Yoshidumi, Y.; Furuie, S.; Kuroda, E.; Ushikai, M.; Asakawa, A.; et al. Effects of supplementation on food intake, body weight and hepatic metabolites in the citrin/mitochondrial glycerol-3-phosphate dehydrogenase double-knockout mouse model of human citrin deficiency. Mol. Genet. Metab 2012, 107, 322-329.

16. Alfadda, A.; DosSantos, R.A.; Stepanyan, Z.; Marrif, H.; Silva, J.E. Mice with deletion of the mitochondrial glycerol-3-phosphate dehydrogenase gene exhibit a thrifty phenotype: Effect of gender. Am. J. Physiol. Regul. Integr. Comp. Physiol. 2004, 287, R147-R156.

17. DosSantos, R.A.; Alfadda, A.; Eto, K.; Kadowaki, T.; Silva, J.E. Evidence for a compensated thermogenic defect in transgenic mice lacking the mitochondrial glycerol-3-phosphate dehydrogenase gene. Endocrinology 2003, 144, 5469-5479.

18. Gudayol, M.; Vidal-Taboada, J.M.; Usac, E.F.; Costa, A.; Cristobal, P.; Dell'Anna, C.; Oliva, R.; Gomis, R. Detection of a new variant of the mitochondrial glycerol-3-phosphate dehydrogenase gene in Spanish type 2 DM patients. Biochem. Biophys. Res.Commun. 1999, 263, 439-445.

19. Koike, G.; Van, V.P.; Shiozawa, M.; Galli, J.; Li, L.S.; Glaser, A.; Balasubramanyam, A.; Brown, L.J.; Luthman, H.; Szpirer, C.; et al. Genetic mapping and chromosome localization of the rat mitochondrial glycerol-3-phosphate dehydrogenase gene, a candidate for non-insulin-dependent diabetes mellitus. Genomics 1996, 38, 96-99.

20. MacDonald, M.J.; Longacre, M.J.; Langberg, E.C.; Tibell, A.; Kendrick, M.A.; Fukao, T.; Ostenson, C.G. Decreased levels of metabolic enzymes in pancreatic islets of patients with type 2 diabetes. Diabetologia 2009, 52, 1087-1091.

21. Rasschaert, J.; Malaisse-Lagae, F.; Sener, A.; Leclercq-Meyer, V.; Herberg, L.; Malaisse, W.J. Impaired FAD-glycerophosphate dehydrogenase activity in islet and liver homogenates of fa/fa rats. Mol. Cell Biochem. 1994, 135, 137-141.

22. Novials, A.; Vidal, J.; Franco, C.; Ribera, F.; Sener, A.; Malaisse, W.J.; Gomis, R. Mutation in the calcium-binding domain of the mitochondrial glycerophosphate dehydrogenase gene in a family of diabetic subjects. Biochem. Biophys. Res. Commun. 1997, 231, 570-572.

23. Fabregat, M.E.; Benito, C.; Gudayol, M.; Vidal, J.; Gallart, T.; Malaisse, W.J.; Gomis, R. Enzyme-linked immunosorbent assay of autoantibodies against mitochondrial glycerophosphate dehydrogenase in insulin-dependent and non-insulin-dependent diabetic subjects. Biochem. Mol. Med. 1997, 62, 172-177.

24. Daoud, H.; Gruchy, N.; Constans, J.M.; Moussaoui, E.; Saumureau, S.; Bayou, N.; Amy, M.; Vedrine, S.; Vu, P.Y.; Rotig, A.; et al. Haploinsufficiency of the GPD2 gene in a patient with nonsyndromic mental retardation. Hum. Genet. 2009, 124, 649-658.

25. Barge-Schaapveld, D.Q.; Ofman, R.; Knegt, A.C.; Alders, M.; Hohne, W.; Kemp, S.; Hennekam, R.C. Intellectual disability and hemizygous GPD2 mutation. Am. J. Med. Genet. A 2013, 161A, 1044-1050.

26. Oliveira, H.C.; Cosso, R.G.; Alberici, L.C.; Maciel, E.N.; Salerno, A.G.; Dorighello, G.G.; Velho, J.A.; de Faria, E.C.; Vercesi, A.E. Oxidative stress in atherosclerosis-prone mouse is due to low antioxidant capacity of mitochondria. FASEB J. 2005, 19, 278-280.

27. Cussenot, O.; Berthon, P.; Berger, R.; Mowszowicz, I.; Faille, A.; Hojman, F.; Teillac, P.; Le, D.A.; Calvo, F. Immortalization of human adult normal prostatic epithelial cells by liposomes containing large T-SV40 gene. J. Urol. 1991, 146, 881-886. 
28. Zhou, M.; Diwu, Z.; Panchuk-Voloshina, N.; Haugland, R.P. A stable nonfluorescent derivative of resorufin for the fluorometric determination of trace hydrogen peroxide: Applications in detecting the activity of phagocyte NADPH oxidase and other oxidases. Anal. Biochem. 1997, 253, 162-168.

29. Benz, R.; McLaughlin, S. The molecular mechanism of action of the proton ionophore FCCP (carbonylcyanide p-trifluoromethoxyphenylhydrazone). Biophys. J. 1983, 41, 381-398.

30. Zhang, J.H.; Chung, T.D.; Oldenburg, K.R. A simple statistical parameter for use in evaluation and validation of high throughput screening assays. J. Biomol. Screen. 1999, 4, 67-73.

31. Bhandari, P.; Gowrishankar, J. An Escherichia coli host strain useful for efficient overproduction of cloned gene products with $\mathrm{NaCl}$ as the inducer. J. Bacteriol. 1997, 179, 4403-4406.

32. Brown, L.J.; Koza, R.A.; Everett, C.; Reitman, M.L.; Marshall, L.; Fahien, L.A.; Kozak, L.P.; MacDonald, M.J. Normal thyroid thermogenesis but reduced viability and adiposity in mice lacking the mitochondrial glycerol phosphate dehydrogenase. J. Biol. Chem. 2002, 277, 32892-32898.

33. Chowdhury, S.K.; Raha, S.; Tarnopolsky, M.A.; Singh, G. Increased expression of mitochondrial glycerophosphate dehydrogenase and antioxidant enzymes in prostate cancer cell lines/cancer. Free Radic. Res. 2007, 41, 1116-1124.

34. Colussi, T.; Parsonage, D.; Boles, W.; Matsuoka, T.; Mallett, T.C.; Karplus, P.A.; Claiborne, A. Structure of alpha-glycerophosphate oxidase from Streptococcus sp.: A template for the mitochondrial alpha-glycerophosphate dehydrogenase. Biochemistry 2008, 47, 965-977.

35. Cole, E.S.; Lepp, C.A.; Holohan, P.D.; Fondy, T.P. Isolation and characterization of flavin-linked glycerol-3-phosphate dehydrogenase from rabbit skeletal muscle mitochondria and comparison with the enzyme from rabbit brain. J. Biol. Chem. 1978, 253, 7952-7959.

36. Garrib, A.; McMurray, W.C. Purification and characterization of glycerol-3-phosphate dehydrogenase (flavin-linked) from rat liver mitochondria. J. Biol. Chem. 1986, 261, 8042-8048.

37. Preston, T.J.; Muller, W.J.; Singh, G. Scavenging of extracellular $\mathrm{H}_{2} \mathrm{O}_{2}$ by catalase inhibits the proliferation of HER-2/Neu-transformed rat-1 fibroblasts through the induction of a stress response. J. Biol. Chem. 2001, 276, 9558-9564.

38. Ricci, G.; De, M.F.; Antonini, G.; Turella, P.; Bullo, A.; Stella, L.; Filomeni, G.; Federici, G.; Caccuri, A.M. 7-Nitro-2,1,3-benzoxadiazole derivatives, a new class of suicide inhibitors for glutathione S-transferases. Mechanism of action of potential anticancer drugs. J. Biol. Chem. 2005, 280, 26397-26405.

39. Seaton, A.; Higgins, C.; Mann, J.; Baron, A.; Bailly, C.; Neidle, S.; van den Berg, H. Mechanistic and anti-proliferative studies of two novel, biologically active bis-benzimidazoles. Eur. J. Cancer 2003, 39, 2548-2555.

40. Dionisi, O.; Cittadini, A.; Gelmuzzi, G.; Galeotti, T.; Terranova, T. The role of the alpha-glycerophosphate shuttle in the reoxidation of cytosolic NADH in Ehrlich ascites tumour cells. Biochim. Biophys. Acta 1970, 216, 71-79.

41. Hunt, S.M.; Osnos, M.; Rivlin, R.S. Thyroid hormone regulation of mitochondrial alpha-glycerophosphate dehydrogenase in liver and hepatoma. Cancer Res. 1970, 30, 1764-1768. 
42. Karsten, U.; Sydow, G.; Wollenberger, A.; Graffi, A. Rat liver glycerolphosphate dehydrogenases: Activity changes and induction by thyroid hormone of the mitochondrial enzyme in hepatomas and in precancerous and growing liver. Acta Biol. Med. Ger. 1971, 26, 1131-1140.

43. Peron, F.G.; Haksar, A.; Lin, M.; Kupfer, D.; Robidoux, W., Jr.; Kimmel, G.; Bedigian, E. Studies on respiration and 11 beta-hydroxylation of deoxycorticosterone in mitochondria and intact cells isolated from the Snell adrenocortical carcinoma 494. Cancer Res. 1974, 34, 2711-2719.

44. Abraham, S.; Bartley, J.; DeOme, K.B.; Faulkin, L.J., Jr.; Medina, D. Enzyme activities in induced and serially transplanted murine mammary adenocarcinomas. J. Natl. Cancer Inst. 1973, 51, 251-256.

45. Criss, W.E. Control of the adenylate charge in the Morris "minimal-deviation" hepatomas. Cancer Res. 1973, 33, 51-56.

46. Harding, J.W., Jr.; Pyeritz, E.A.; Morris, H.P.; White, H.B., III. Proportional activities of glycerol kinase and glycerol 3-phosphate dehydrogenase in rat hepatomas. Biochem. J. 1975, 148, 545-550.

47. Shonk, C.E.; Arison, R.N.; Koven, B.J.; Majima, H.; Boxer, G.E. Enzyme patterns in human tissues. 3. Glycolytic enzymes in normal and malignant tissues of the colon and rectum. Cancer Res. 1965, 25, 206-213.

48. Shonk, C.E.; Morris, H.P.; Boxer, G.E. Patterns of glycolytic enzymes in rat liver and hepatoma. Cancer Res. 1965, 25, 671-676.

49. Liu, Y. Fatty acid oxidation is a dominant bioenergetic pathway in prostate cancer. Prostate Cancer Prostatic. Dis. 2006, 9, 230-234.

50. Katusic, Z.S.; Vanhoutte, P.M. Superoxide anion and endothelial regulation of arterial tone. Semin. Perinatol. 1991, 15, 30-33.

51. Glass, C.K.; Witztum, J.L. Atherosclerosis. the road ahead. Cell 2001, 104, 503-516.

52. Fulda, S.; Galluzzi, L.; Kroemer, G. Targeting mitochondria for cancer therapy. Nat. Rev. Drug Discov. 2010, 9, 447-464.

53. Kroemer, G. Mitochondria in cancer. Oncogene 2006, 25, 4630-4632.

54. Trachootham, D.; Alexandre, J.; Huang, P. Targeting cancer cells by ROS-mediated mechanisms: A radical therapeutic approach? Nat. Rev. Drug Discov. 2009, 8, 579-591.

(C) 2014 by the authors; licensee MDPI, Basel, Switzerland. This article is an open access article distributed under the terms and conditions of the Creative Commons Attribution license (http://creativecommons.org/licenses/by/3.0/). 